\title{
ENTRE PABLO NERUDA Y RIGOBERTA MENCHÚ. REPRESENTACIONES DEL PASADO PRECOLOMBINO EN MUSEOS DE CHILE
}

\author{
BETWEEN PABLO NERUDA AND RIGOBERTA MENCHÚ. REPRESENTATIONS \\ OF THE PRECOLOMBIAN PAST IN MUSEUMS OF CHILE
}

\author{
Jacqueline Correa-Lau', Javiera Carmona ${ }^{2}$, Gabriela Carmona ${ }^{3}$, \\ Victoria Castro $^{4,5}$ y Calogero M. Santoro ${ }^{1 *}$
}

\begin{abstract}
Se examina los usos y modos de representación de las culturas precolombinas y de los pueblos indígenas en un grupo de museos arqueológicos de Chile a partir de una lectura crítica que abarca desde el siglo XIX hasta el siglo XXI. El presente de los museos arqueológicos se observa desde la complejidad de las relaciones entre los objetos culturales precolombinos que exhiben y las sociedades indígenas pasadas y presentes, sobre las cuales se elaboró una clasificación expresada en las dos posiciones que se derivan de sus discursos y prácticas museológicas. En la primera, los criterios científicos predominan en la concepción museológica y evoca una frase del verso del poeta chileno Pablo Neruda en Alturas de Machu Picchu: "Vengo a hablar por vuestra boca muerta". La segunda se caracteriza por un enfoque inclusivo que reconoce la necesidad de desarrollar propuestas museísticas con y para las comunidades indígenas y no indígenas, y se refiere a la afirmación autobiográfica de Rigoberta Menchú de dar su propia visión de la historia de su pueblo: "mi situación personal abarca toda la realidad de un pueblo". También se compara la experiencia chilena y el fenómeno museológico de los museos comunitarios de México (i.e. Oaxaca) entendidos como una alternativa válida de nuevas pautas en los discursos curatoriales, sobre las representaciones de los pueblos indígenas prehispánicos y actuales, a ser adoptadas por los museos chilenos. En suma, como parte de la tendencia generalizada a incorporar los pensamientos y enfoques de las comunidades indígenas en el trabajo museológico, el objetivo del artículo es problematizar el sistema de museos arqueológicos chilenos y analizar la relación dinámica entre la agencia del museo, sus actores sociales y las condiciones contextuales que particularizan su experiencia, cuya comprensión es significativa en la proyección de eventuales transformaciones, lo que si bien se reconoce como asunto urgente, son pocos los ejemplos que se han mantenido a lo largo del tiempo en Chile.
\end{abstract}

Palabras claves: museología, museos arqueológicos chilenos, comunidades indígenas, museos comunitarios de México.

It examines the uses and modes of representation of pre-Columbian cultures and indigenous peoples in a group of archaeological museums in Chile from a critical reading covering from the nineteenth to the twenty-first century. The present of the archaeological museums is observed from the complexity of the relations between the pre-Columbian cultural objects they exhibit and past and present indigenous societies, on which a classification was elaborated expressed in the two positions that are derived from their discourses and museological practices. In the first, scientific criteria predominate in the museological conception and evokes a phrase from the verse of the Chilean poet Pablo Neruda in Alturas de Machu Picchu: "I come to speak for your dead mouth". The second is characterized by an inclusive approach that recognizes the need to develop museum proposals with and for indigenous and non-indigenous communities, and refers to Rigoberta Menchú's claim in her autobiography for giving her own vision of the history of her people: "my personal situation encompasses the whole reality of a people". We also compare the Chilean experience and the museological phenomenon of the community museums of Mexico (i.e. Oaxaca) understood as a valid alternative of new guidelines in the curatorial discourses, on the representations of pre-Hispanic and present native peoples, to be adopted by the Chilean museums. In sum, as part of the widespread tendency to incorporate the thoughts and approaches of indigenous communities into museological work, the aim of the article is to problematize the system of Chilean archaeological museums and to analyze the dynamic relationship between the museum's agency, its social actors and the contextual conditions that particularize its experience, whose understanding is significant in the projection of eventual transformations, which, although recognized as urgent matters, few examples have been maintained over time in Chile.

Key words: Museology, pre-Columbian societies, Chilean museums, indigenous communities, community museums of Mexico.

\footnotetext{
${ }^{1}$ Instituto de Alta Investigación, Universidad de Tarapacá, Arica, Chile. lau1568@gmail.com; *autor correspondiente: calogero_santoro@yahoo.com ${ }^{2}$ Departamento de Ciencias de la Comunicación, Museo Universitario del Grabado UPLA, Universidad de Playa Ancha, Valparaíso, Chile. javiera.carmona@upla.cl

3 Museo del Limarí, Servicio Nacional del Patrimonio Cultural, Ovalle, Chile. gabrielacarmos@ yahoo.es

${ }^{4}$ Departamento de Antropología, Universidad Alberto Hurtado, Santiago, Chile. vcastror53@ gmail.com

${ }^{5}$ Departamento de Antropología Universidad de Chile, Santiago, Chile.
}

Recibido: enero 2018. Aceptado: diciembre 2018.

http://dx.doi.org/10.4067/S0717-73562019005001702. Publicado en línea: 6-agosto-2019. 
Presentamos un recorrido entre los siglos XIX y $\mathrm{XXI}$ sobre los modos en que las culturas precolombinas y los pueblos originarios han sido caracterizados y representados en museos arqueológicos de Chile, estatales y privados, ejemplificados a través de una muestra del norte, centro y sur del país. Se trata de un análisis descriptivo sobre la misión de la investigación y la exhibición de las culturas y sociedades precolombinas, ligadas a las lógicas del poder-saber en las formas de auto descripción de la nación y las élites o grupos de poder del Estado y la opción de los propios museos por establecer una relación entre los objetos culturales precolombinos y las sociedades indígenas contemporáneas. A nuestro juicio, estos factores han influido en la forma cómo se representan las sociedades indígenas en los museos y en la relación que tenemos como país respecto a dichas comunidades y el patrimonio arqueológico; lo que se contrasta con México donde la relación más cercana con las comunidades y el pasado precolombino ha derivado en el desarrollo de museos comunitarios que se presentan como una alternativa en este debate. El análisis es de tipo socio-histórico centrado en la constante interacción entre los actores sociales ligados al museo (quienes le confieren agencia a la institución) y los condicionantes exteriores contextuales que impactan en la museografía, y en la definición y apego al enfoque museológico que declaran.

Este estudio surgió de la convocatoria realizada por el Institute of Andean Reseach para debatir a nivel de los países andinos una serie de interrogantes que se resumen a continuación: (a) ¿Cómo las culturas y civilizaciones precolombinas son (o han sido) caracterizadas y representadas en algunos museos arqueológicos de Chile?,(b) ¿Cómo podemos entender y fomentar la misión de la investigación y exhibición de las culturas y sociedades precolombinas?, (c) ¿En qué medida les concierne a los museos arqueológicos establecer una relación entre los objetos culturales precolombinos y las sociedades indígenas contemporáneas?

En el análisis se identifican los elementos de la política de representación museológica de las culturas prehispánicas y se intenta demostrar que se trata de una visión única y homogénea legitimada por el cientificismo académico, amplificado en la consolidación y reproducción de un imaginario común de carácter nacional ligado a la idea de patria. Estos principios se prolongan durante el siglo XX hasta que emerge la discusión sobre nuevas formas de entender y abordar la representación del pasado al iniciar el siglo XXI. Las prácticas curatoriales en los museos arqueológicos chilenos actuales se debaten entre el apego a esta política de la representación heredada y el esfuerzo por construir nuevos discursos expositivos.
Este desafío en algunos museos ha logrado materializarse de manera exitosa, pero en muchos otros casos ha derivado más bien en propuestas contradictorias y faltas de coherencia.

Para examinar este escenario se analizaron 10 museos arqueológicos y etnográficos que se clasificaron en dos categorías inspiradas, por un lado, en un verso de Pablo Neruda y, por otro, en una frase de la líder quiché Rigoberta Menchú. Esta experiencia chilena se contrasta con la de los museos comunitarios de Oaxaca, México, que constituye un caso de genuino interés de las comunidades por apropiarse de su patrimonio en el proceso de auto reconocimiento y construcción de sentido colectivo y autónomo.

\section{Usos y Representaciones del Pasado Precolombino en Museos de Chile entre los Siglos XIX y XX}

El siglo XIX fue el período emblemático en el que irrumpieron los museos nacionales de historia natural en América del Sur y se erigieron en lugares privilegiados de la infraestructura de las ciencias y saber (Podgorny y Lopes 2013) en un contexto definido por el nacionalismo y la macropolítica expansionista de los estados liberales tutelados por las oligarquías regionales. Para 1830, en la agenda política de país independiente se subrayó la condición de descolonialización, apuntalada por el desarrollo científico situado en el espacio museístico, el que tendió a imitar a los museos de Europa. El gobierno chileno encargó al naturalista francés Claudio Gay el gran estudio sobre la geografía, geología, demografía y actividades productivas del territorio chileno y que dio origen a la nutrida colección con la que se fundó en 1838 el Museo Nacional, antecesor del Museo Nacional de Historia Natural creado en 1911. Para el Estado chileno, la obra de Gay estaba destinada a estimular la inversión e inmigración europea y mostrar a los propios chilenos la esencia de su país basada en el valor de sus recursos naturales y la de los padres de la emancipación de la monarquía hispana. Con ello se certificó la unión entre ciencia y patria en torno al flamante y recién creado "patrimonio nacional" (Molloy 2005), ligazón que se mantuvo en el siglo XX al formalmente constituirse la arqueología como disciplina científica. La colección de Gay para el Museo Nacional abarcó minerales, plantas y la cultura material de los pueblos indígenas, visto como un conjunto de evidencias de la excepcionalidad del nuevo Estado-nación. El público del Museo Nacional fue la élite chilena que lo reconoció como símbolo del progreso y del proyecto nacional moderno que dejaba en el pasado a la pobre colonia hispana (Schell 2001). En esta valoración las colecciones arqueológicas 
y etnográficas carecían de interés mientras el Estado desplegaba su política de subyugación de los pueblos originarios para añadir sus territorios a la nueva cartografía nacional. En la segunda mitad del siglo XIX el Estado se extendió hacia Tierra del Fuego y Rapa Nui (1888), selló en la Araucanía la "pacificación" (1884) con la reducción de los Mapuche y en el extremo norte ocupó la zona salitrera de Tarapacá y Antofagasta -mediando la Guerra del Pacífico- y asimiló a los grupos indígenas auto reconocidos en la actualidad como quechua, aymara y atacameño. Las últimas décadas del siglo XIX chileno se caracterizaron por situar lo indígena en el campo del patrimonio de la nación, y como institución pública el Museo Nacional expuso y reafirmó en su discurso museológico la violencia simbólica y física ejercida por el Estado (Alegría et al. 2009). La exhibición de cuerpos indígenas vivos y de restos momificados refleja la fuerza de la violencia biopolítica del Estado en las prácticas museológicas decimonónicas como en la exposición de supuestos antropófagos en 1873 organizada por Benjamín Vicuña Mackenna en Santiago (Hernández 2006:246). Con ello se ratificaba la oposición salvajes/civilizados que conduciría al intento de integrar a los primeros en el proyecto de modernización de la nación (Navarro 2006). El menosprecio por el pasado precolombino y los pueblos originarios provocó un vacío en el discurso de identidad nacional que fue ocupado por las élites y la exaltación de su pasado colonial (Yaeger 2009:131132), de modo que la exposición de Vicuña Mackenna con la colección de tesoros coloniales pertenecientes al grupo de poder dominante, presentó ante la clase media y el pueblo su linaje ilustre y sus propios bienes como patrimonio de toda la nación, acentuando hasta el paroxismo la división de clases como un componente histórico e inmanente de la identidad chilena resolviendo en lo concreto el hiato que dejó la negación de la alteridad que aportaba el componente indígena.

En 1874 Rodulfo A. Philippi, como nuevo director del Museo Nacional y migrante alemán, comenzó a adecuar la colección para representar a Chile desde su visión sobre la naturaleza del país y su relación con la comunidad científica internacional (Schell 2001:47). Philippi se centró en presentar ejemplos de la historia natural y cultura indígena en todas sus formas y la rareza de las "antigüedades indígenas" de Chile en comparación con las de Perú, Bolivia y México (Schell 2001). El conjunto de objetos históricos, prehistóricos e indígenas naturalizaron el concepto de la nación chilena y lo equipararon con una realidad geográfica que abarcaba minerales, fósiles, animales, objetos y cuerpos indígenas (Schell 2001:53). El discurso museológico transcurría sobre una línea temporal que concluía felizmente después de siglos de desarrollo lineal y progresivo, y reafirmaba a Chile como potencia colonial, fortalecida al musealizar la cultura indígena contemporánea advirtiendo que estos grupos conflictivos y primitivos se encontraban destinados a extinguirse en la lógica darwinista por pertenecer a un estadio de desarrollo inferior. La pacificación de la Araucanía que finalizó en 1897 legitimó la idea del ocaso de los Mapuche y profundizó el ya reducido interés por los restos de una cultura considerada muerta por el Estado (Crow 2009; Gil 2016), al punto de omitir ese año en el catálogo del Museo la descripción de la colección etnográfica. Con el retiro de Philippi la muestra etnográfica perdió interés para el Museo Nacional, en contraste con la atención que manifestaban los etnógrafos extranjeros que acudían regularmente a examinar la colección en el marco del creciente interés científico europeo por el pasado precolombino sudamericano y las culturas indígenas aún vivas que motivaron numerosas expediciones. Esta línea argumental permitiría indagar sobre las razones por las que no se fundó en Chile un museo nacional de arqueología, asociada también a la accidentada vida del único museo de etnología y antropología creado en 1912 y cerrado en 1929.

Con acentos y énfasis variables a lo largo del tiempo, la visión decimonónica única y desdeñosa del pasado precolombino y del presente indígena, así como la concepción homogeneizadora de la identidad chilena, apuntalada por la academia, se sostuvo durante el siglo XX junto al aumento de museos estatales (bellas artes, historia). La irrupción de las masas con grandes carencias que incrementaron la conflictividad social caracterizó el inicio del siglo, escenario en el que los museos comenzaron a dirigir sus acciones hacia este nuevo público, que había que educar, controlar y disciplinar en torno a las normas de sociabilidad urbana para revertir "los malos hábitos del pueblo" (Gazmuri 2001). El desplazamiento progresivo de la actividad científica hacia las universidades contribuyó a la consolidación de la concepción de las instituciones museísticas como espacio para educar a las masas sobre el desarrollo científico y tecnológico en la perspectiva del proyecto de industrialización del país. Asimismo, el discurso museológico proponía conciliar la continuidad y el cambio en la historia de Chile, la tradición y la modernidad y exceder a las élites en su protagonismo al incorporar otros sectores excluidos de la sociedad (mujeres, pueblos originarios y extranjeros). La Exposición Histórica del Centenario de 1910 reflejó este criterio a través de diversas secciones (útiles de artes manuales, objetos indígenas, tejidos, trajes y joyas) que representaban un paisaje sociocultural más diverso, basado en la inclusión abstracta y la exclusión concreta (Alegría y Núñez 2007:73). Mientras los retratos, uniformes 
e insignias militares abarcaron la mayor parte de la muestra, las piezas arqueológicas y etnográficas fueron arrinconadas y casi marginadas originando un debate que se dio en la prensa regional del norte del país y no en la capital, sobre la importancia de las ciencias arqueológicas en Chile (Alegría y Núñez 2007:79). En este marco se verificó tanto la instalación de una agenda científica para la arqueología y antropología chilena, y la creciente disputa conceptual sobre el patrimonio arqueológico y etnográfico en cuanto emergió una oposición de científicos e intelectuales de raíz laica e iluminista que impugnó al sector conservador de la intelectualidad chilena (Subercaseaux 2000:77-78), activa en patrimonializar cualquier objeto que honrara la historia nacional y que a la vez ocupara el pasado indígena para dotar a su narrativa de profundidad temporal. Una de las facciones de las fuerzas en oposición del ámbito intelectual representada por el campo científico de la prehistoria, logró la fundación del Museo de Etnología y Antropología de Chile en 1912 en la línea de las instituciones museísticas etnológicas de la era colonialista europea. El museo no tuvo carácter "nacional" y su precariedad institucional se expresó en la situación de itinerancia que mantuvo hasta su cierre en 1929, trasladándose sus colecciones entre distintos recintos mientras se inauguraron grandes obras como la Biblioteca Nacional en 1925.

La experiencia del Museo de Etnología -conducido por Max Uhle hasta 1917- vista desde la relación entre el saber, las instituciones y el poder, responde al contexto político centrado en la realización de reformas sociales planificadas pero desprovistas de recursos, marco en el que se desestimó el papel de la arqueología, de la institución museística y su discurso sobre el pasado precolombino en el proyecto político del Estado con respecto a la consolidación de la identidad nacional, en clara oposición a lo sucedido en Bolivia, Perú o México (Earle 2006; Gnecco 2008; Mamani 1989). La aparición de los museos regionales a partir de la década de 1950 señala la importancia que entonces adquirió para el Estado la arqueología y las instituciones museísticas en sus políticas de chilenización de los territorios del norte del país (Salazar et al. 2011). El discurso científico sobre el patrimonio indígena y su proyección en el museológico colaboraron con la estabilidad del proceso de dominación del Estado en el plano ideológico, legal y pragmático, referido al control del paisaje y la reducción de los grupos indígenas (Podgorny y Politis 1992). Así, durante la dictadura cívicomilitar de las décadas de 1970 y 1980 el avance del "blanqueamiento" de las poblaciones indígenas expresado en la negación de sus orígenes se intensificó, sin revertirse el maltrato y discriminación hacia estos grupos con el advenimiento de la democracia desde 1992. Los discursos museológicos estatales y las representaciones del pasado precolombino herederas de la visión hegemónica y academicista se mantuvieron imperturbables como en las décadas precedentes, en un escenario de precariedad de recursos compartidos entre los museos estatales. En la década de los 2000 el Estado chileno comenzó la renovación museológica y museográfica de sus instituciones, centradas en la idea de la nación multicultural en un proceso en el que se patrimonializa la cultura indígena, usando y reproduciendo la autoridad científica de la arqueología para autentificar y legitimar identidades étnicas y nacionales. El discurso museológico continúa reproduciendo, e incluso fortalece, las relaciones coloniales de dominación, aunque ya no desde la negación y exclusión de antaño sino desde la inclusión (Ayala 2014). El siglo XXI se distingue como un cambio de época en el que las comunidades indígenas se reconocen a sí mismas en su triple dimensión, como público de museos, como centro de las narrativas museísticas y como sujetos de estos rastros enunciativos. El reclamo por mayor control sobre la interpretación, gestión y manejo de su patrimonio cultural revela la profundidad y complejidad del contexto que enfrentan los museos arqueológicos y etnográficos ante la ciudadanía contemporánea chilena. Las prácticas curatoriales actuales se debaten entre el apego a esta política de la representación heredada y el esfuerzo por construir nuevos discursos expositivos.

De acuerdo al registro de museos del Servicio Nacional del Patrimonio Cultural (SNPC) -que es voluntario y no exhaustivo-, en Chile habría 264 museos inscritos, y 136 corresponderían a museos de arqueología, antropología y etnografía (SNPC 2019). Casi el $45 \%$ de ellos son estatales, mientras que el resto pertenecen a privados (corporaciones, fundaciones o comunidades indígenas). Las misiones que declaran los museos estatales y privados analizados coinciden en las tareas de resguardar y estudiar los restos materiales de una memoria histórica remota, aparentemente olvidada o desconocida para la mayoría de la población.

Dichos museos, desarrollan su quehacer en un escenario en el que se acrecientan las aprehensiones sobre el efectivo cumplimiento de fomentar la inclusión y la participación como parte de las problemáticas museológicas contemporáneas, concernientes a las representaciones del patrimonio. La posición del museo univocal, asituado, aproblemático y desterritorializado, sin embargo, se mantiene como principio del discurso curatorial predominante y se ve enfrentado a los discursos emergentes de los museos que intentan responder a estas demandas sociales.

Para problematizar los discursos y curadurías de los museos arqueológicos respecto a la representación del pasado precolombino, se proponen dos categorías de análisis metafóricamente inspiradas en un verso 
de la obra poética Alturas de Machu Picchu (1950) de Pablo Neruda y en una frase de la biografía de Rigoberta Menchú. Si bien ninguno de los dos hizo alusiones al debate museológico latinoamericano, utilizamos sus palabras para categorizar las relaciones entre los elementos de los discursos museológicos y sus prácticas museográficas. En el verso que incluye la frase "Yo vengo a hablar por vuestra boca muerta" (Neruda 2005:45), Neruda asume la búsqueda de lo espiritual y viviente de los seres que tuvieron la experiencia de construir y resistir la vida desigual que él imaginó para Machu Picchu en el esfuerzo por devolverles en su propia obra un espacio de representación.

\section{Hablar por las Bocas Muertas}

El de "hablar por los otros que ya no tienen voz" es la expresión que adoptamos para referirnos a la propuesta museológica dominante en los museos arqueológicos regionales, la que se caracteriza por tratar de mostrar la mayor cantidad de objetos posibles como forma de cumplir con la misión de "divulgar el conocimiento de la prehistoria local chilena, colaborar con la educación y la cultura nacional, y preservar el patrimonio arqueológico e histórico de Chile", como enuncia el Museo Arqueológico de Los Andes (SNPC 2019) y el Museo de Punta Morhuilla que plantea "conservar el patrimonio cultural de Punta Morhuilla y darlo a conocer a los visitantes de nuestra provincia" (SNPC 2019), seleccionados para esta análisis.

Los museos arqueológicos examinados también se caracterizan por estar respaldados por ricas colecciones de hallazgos in situ que pueden derivar en investigaciones científicas cuyo conocimiento se vuelve central en los discursos curatoriales enfocados en documentar la vida económica, tecnológica, ideológica y de organización social de los pueblos precolombinos, orden clasificatorio cientificista. Estos museos fueron fundados por iniciativas privadas y luego tutelados por universidades regionales, el municipio o el Estado a través del SNPC. La proyección del conocimiento en la exhibición revela la autoridad de los especialistas para "hablar por las bocas muertas" de los pueblos originarios, y también señala prácticas museográficas intuitivas, basadas en la voluntad autoformativa, en el aprendizaje en el hacer, disociadas de la conceptualización museológica; tendencia que se repite en Latinoamérica (DeCarli 2008).

Con respecto a la concepción de los públicos por parte de la mayoría de los museos arqueológicos, los especialistas en su posición de autoridad definen unilateralmente los intereses de estos sin mediar estudio o conocimiento de sus perfiles (motivaciones, expectativas, ideas preconcebidas) previo al diseño de la propuesta curatorial. Los públicos son asumidos en un rol pasivo, contemplativo, como receptores de un discurso más intelectualizado que problematizado. Los especialistas que trabajan en los museos que nosotros categorizamos como "visión nerudiana" asumen la responsabilidad de reponer la voz de los silenciados con la visión y lenguaje academicista que les es propio, con la intención de elaborar un discurso que -desde su punto de vista y de acuerdo al contextopermitiría una mejor comprensión y reflexión sobre el pasado.

\section{La Voz Propia de Rigoberta Menchú}

Una minoría de los museos arqueológicos registrados en el SNPC consideramos que propone discursos y desarrolla prácticas museológicas que privilegian la "voz propia" de las comunidades; rasgo que corresponderían a la visión del relato biográfico (1985) de Rigoberta Menchú, quien sostuvo que "... trataré de dar un poco mi historia. Mi situación personal engloba toda la realidad de un pueblo" (Burgos 2007:21). Menchú insistió en la necesidad y voluntad de entregar su propia visión respecto de la historia de su pueblo basada en su experiencia, en sus concepciones culturales, en su saber.

Los ocho ejemplos seleccionados corresponden a museos clasificados como arqueológicos y etnográficos de acuerdo a las características de su colección, y tienen en común que han surgido por iniciativa de pequeñas comunidades, grupos e incluso individuos. $\mathrm{Al}$ revisar estas experiencias se observa las contradicciones y nudos críticos de proyectos presentados como comunitarios y participativos pero que en algunos casos no logran desplegar prácticas museográficas distintas, ni representaciones del pasado divergentes en nuevos discursos expositivos.

El Museo Mapuche de Cañete (llamado desde 2010 Ruka Kimvn Taiñ Volil- Juan Cayupi Huechicura) es una institución estatal al sur de Chile que desde su fundación en 1969 ha sido permeable al tenor de las relaciones entre el Estado y las comunidades indígenas. El nombramiento de Juana Paillalef, de origen Mapuche, en la dirección del museo inició una transformación profunda desde 2001 a través de un proceso de deconstrucción sobre su trayectoria como institución colonial para luego reorientar su proyecto museológico conducido por la propia comunidad para mostrar la cultura de la comunidad mapuche local. La reforma y reinterpretación del museo plantea una serie de dilemas sobre los alcances y restricciones del multiculturalismo neoliberal que ha impulsado el Estado chileno (Crow 2011). 
El discurso museológico del Museo Martín Gusinde de Puerto William ofrece otra experiencia estatal que desarrolla nuevas representaciones sobre el pasado. El museo se posiciona contra el discurso hegemónico y oficial de la extinción de la cultura yagán, y subraya la profundidad del mestizaje en este territorio con la participación de la propia comunidad. Previo a las exposiciones temporales el museo ha conformado grupos de investigación entre especialistas y mujeres de la comunidad (MCAP 2016). Los antiguos retratos de los últimos descendientes de la comunidad yagán fueron examinados por los familiares herederos quienes identificaron a sus antecesores, los lugares y circunstancias en las que fueron capturadas las imágenes, ligada a una investigación documental sobre la memoria grupal que rebate la idea de la completa extinción de los yaganes. Esta experiencia consistió en una concepción museología y práctica museográfica participativa que valoró el aporte biográfico de los descendientes de las comunidades, mientras que resignifica la información de los archivos documentales de la misma institución y recoge los nuevos datos en los cedularios del recorrido museográfico.

El Museo Indígena Atacameño de Arqueología y Etnografía, Valle de Lasana en el Alto Loa, es el primer museo estrictamente indígena según los habitantes del lugar porque la iniciativa nació de la propia comunidad que se siente depositaria de las tradiciones prehispánicas referidas a la agricultura, vestimenta (textiles) y ceremonias vinculadas a la tierra y a los astros. Este museo privado está ubicado en un espacio de atractivo turístico por su proximidad al Pukara de Lasana, parte de la red vial andina de la época Inca Qhapaq Ñan, y por la gran riqueza de petroglifos del sector. El propósito del museo estriba en mostrar las tradiciones y costumbres ancestrales con el objetivo de exhibir, mantener y difundir las antiguas ocupaciones de cazadores recolectores, las construcciones Incas y los adelantos tecnológicos que se mantienen hasta nuestros días. La comunidad concibe al museo como un agente de promoción cultural así como dinamizador de la incipiente industria de turismo patrimonial: "Queremos que Lasana pueda desarrollar un espacio para su cultura y que también signifique un nuevo punto que los turistas que llegan a la provincia puedan apreciar" (SNPC 2019). Esta propuesta museográfica, sin embargo se inscribe en el discurso cientificista que propone en una temporalidad lineal de poco más de dos mil años el desarrollo cultural y evolutivo del territorio.

La experiencia del Museo Municipal de Pica, ubicado también al norte de Chile, se fundó para velar por "la protección histórica y arqueológica, mediante el desarrollo de proyectos de investigación". Pese a esta definición, el museo creó recientemente un depósito de colecciones complementario al existente para ubicar en un espacio con óptimas condiciones de conservación los objetos arqueológicos. Financiado por el Ministerio de las Culturas, las Artes y el Patrimonio (FONDART Regional), a través de metodologías participativas, la ejecución del depósito activó en la comunidad un proceso de valoración, concientización y respeto sobre el patrimonio cultural, arremetiendo contra el desconocimiento y bajo interés sobre este patrimonio arqueológico que los especialistas y algunos miembros de la comunidad percibían entre los habitantes de Pica. El proyecto incluyó capacitación en museología para los miembros de la comunidad que integrarían el equipo de trabajo al que se sumaron como ayudantes niñas, niños y jóvenes de la escuela San Andrés de Pica que asumió un compromiso colectivo en la protección y salvaguarda de sus bienes culturales. Esta experiencia surge de la negociación de expectativas entre un sector de la comunidad piqueña y las especialistas, lo que relativiza la perspectiva unilateral y dirigista con la que se inició la interacción.

El Museo Comunitario Despierta Hermano, ubicado en Malalhue, en territorio Mapuche, es un ejemplo de propuesta comunitaria-escolar que nació 1996 por el interés y esfuerzo de un grupo de ex estudiantes del Liceo República del Brasil de Lanco. Gracias al financiamiento de la Comisión Nacional de Desarrollo Indígena (CONADI) y el apoyo de diversas comunidades Mapuche este museo cuenta con piezas arqueológicas. El museo propone "rescatar la memoria de la cultura Mapuche, recordar y hacer presente la pertenencia de este pueblo a la comunidad" (Red de Museos de la Región de Los Ríos 2019). La museografía se aleja de la impronta cientificista y reproduce de manera más libre un gran baúl familiar que custodia objetos conservados y legados a lo largo del tiempo entre los miembros de las comunidades, subrayando que la colección se ha conformado por donaciones de piezas arqueológicas y objetos históricos que ellos consideran deben ser socializados con las nuevas generaciones. El propósito es fortalecer y compartir la identidad de todos los que integran la comunidad malahuina, declaración que revela la propuesta de ajuste o ligazón entre una identidad indígena y una territorial en la que finalmente se constituye la comunidad.

El Museo Leandro Penchulef, situado en la sede Villarrica de la Pontificia Universidad Católica de Chile, tiene como finalidad "el encuentro, la reflexión e interacción en torno a la historia, memoria histórica, patrimonio cultural y situación actual de las relaciones chileno-Mapuche" (Museo Leandro Penchulef 2014). La motivación para la fundación del Museo en la década de 1980 fue rebatir una nota de la prensa local, 
que sostenía que los Mapuche eran pobres en cultura $\mathrm{y}$ en especial en cuentos, leyendas y tradiciones. $\mathrm{La}$ dirección de la sede universitaria en Villarica levantó un proyecto para reunir antecedentes que desmintieran a la prensa, y que motivara la donación de objetos y la compra por parte de la Universidad. El Museo se inauguró con una exhibición provisoria de objetos ubicados en vitrinas, los que carecían de clasificación, catalogación y estudios específicos y, menos aún, guion museográfico. En el año 2000, la Fundación Andes financió gran parte de la puesta en valor y montaje del actual museo en una política que benefició a otras instituciones museísticas regionales. La puesta en valor y montaje fue realizada por especialistas que diseñaron un trabajo participativo, intercultural e interdisciplinario que incorporó a los miembros de las comunidades Mapuche cercanas y que destacó el valor de la historia local y la memoria oral. Este caso revela el ejercicio de reflexión crítica de los especialistas sobre sus propias prácticas curatoriales en la perspectiva de construir discursos dialógicos y representaciones del pasado ligadas a la experiencia y sentir de las comunidades que comparten el mismo territorio en el que se emplaza el museo.

El Museo Mapuche de Pucón es un museo familiar que enlaza tres generaciones en torno a la misión "dar a conocer la cultura mapuche". A lo largo de un siglo la familia Ulloa-Metzger reunió la colección de alrededor 1.500 piezas arqueológicas (líticas fundamentalmente), dispuestas en un recorrido museográfico dirigido por los integrantes de la familia que narran de manera llana la historia de cada objeto. El museo ofrece una lectura del pasado Mapuche desde un punto de vista indigenista que liga la historia familiar a cada una de las piezas de la colección y al pasado precolombino.

La clasificación no está exenta de dificultades al reconocer que en ocasiones el discurso museológico de la "visión propia" se opone a las prácticas museográficas que responden a lo que hemos denominado "visión nerudiana". Esta tensión se debe a varios factores como las características particulares de los territorios y sus comunidades, los consensos y diferencias entre los especialistas sobre cómo abordar la construcción de relaciones de confianza con las comunidades y la autocrítica sobre las prácticas curatoriales. A esto se suman las restricciones y licencias derivadas de la dependencia formal del museo (Estado, universidad, municipio, privados), y la concepción que tienen de sus públicos.

El último caso a revisar encarna en simultáneo la visión de "hablar por las bocas muertas" de Neruda y de la "voz propia" de Rigoberta Menchú. En agosto de 1997 se inauguró en el Museo Arqueológico San Miguel de Azapa (MASMA) de la Universidad de
Tarapacá, la exposición etnográfica "Ayllu, Vida en las Alturas", que recogió la experiencia cotidiana de comunidades de pastores andinos al interior de Arica. Con esta muestra temporal se intentó dar continuidad a la narrativa de la exhibición permanente del museo "Arica Prehispana", la que por décadas destacó de manera aproblemática y en tiempo lineal la milenaria prehistoria de esta región en el área Centro Sur Andina a partir de las colecciones reunidas por los científicos fundadores del museo en 1957, y las formadas a partir de las investigaciones de los académicos de la universidad (Muñoz y Standen 2018). El relato precolombino finalizaba con la invasión europea del siglo XVI sugiriendo que la historia de estas sociedades se desvaneció tras la conquista, y por tanto carecía de continuidad con las sociedades indígenas contemporáneas.

En la propuesta curatorial de "Ayllu" participaron los miembros de las comunidades andinas, a través del diálogo con los especialistas para mostrar la vida en el altiplano de una comunidad de pastores aymara, la que quedó ceñida a tres ejes (economía tradicional, organización socio-política y religión). Las comunidades además participaron en el montaje museográfico de los escenarios y se apropiaron de la exhibición especialmente durante la ceremonia inaugural, consagrada con ritos andinos de pago o acción de gracias. La exhibición "Ayllu" se propuso "comprender y valorar la riqueza cultural del pueblo aymara, en su acelerado proceso de transformación" (MASMA 2019), en la medida que "desde la conquista hispana, la vida económica, cultural y política de los aymara siguió rumbos impuestos, primero por el sistema colonial y más tarde, hasta ahora, por el republicano" (MASMA 2019). En esta perspectiva, "Ayllu" en efecto proporcionó desde un punto de vista científico la contextualización de los aymara contemporáneos como "herederos de las grandes civilizaciones andinas que desarrollaron complejas formas de organización social y política, que lograron domesticar las condiciones climáticas alto andinas, a través de sistemas agro-ganaderos en un medio estepario y desértico" (MASMA 2019). La génesis de la exposición "Ayllu" corresponde al reconocimiento de los especialistas de un patrimonio en riesgo ante el avance de los procesos de transformación del paisaje cultural que puede no ser evidente para los actores sociales implicados.

"Ayllu" se convirtió en una exposición permanente y la apertura del Museo hacia la comunidad indígena no fue sostenible, convirtiendo la muestra en un testimonio del pasado tanto de la comunidad como del discurso museológico y la práctica curatorial de integración comunidad-museo como actor permanente de la exposición. La experiencia a "dos voces", la nerudiana de "hablar por las bocas muertas" y "la 
voz propia" de Menchú se expresan a través de estas sendas exposiciones. Sin embargo, al pasar los años, el vigor de la experiencia "Ayllu" quedó fosilizada silenciando a las comunidades vivas. Cabe señalar que este museo concibe como público predominante a los turistas nacionales e internacionales, no así las comunidades indígenas.

\section{Hacia una Museología de "la Voz Propia" sobre el Pasado Precolombino y Pueblos Originarios}

Como en el resto de Latinoamérica, Chile y sus museos viven el desafío cotidiano de responder a las inéditas demandas formuladas por las comunidades que reclaman su lugar en la discusión sobre su patrimonio entendida como construcción social integral que abarca entornos naturales, paisajes culturales, sitios históricos, biodiversidad, tradiciones pasadas y presentes, conocimientos y experiencias vitales (ICOMOS 1999). En este contexto de pugna entre la visión restrictiva del patrimonio que ampara la ejecución de acciones homogeneizadoras y artificiosas sobre las ciudades, los objetos y sujetos y, la concepción de los territorios como tejidos vivos, como sistema que expresa un patrimonio habitado y heterogéneo, los museos pueden ser actores significativos en el proceso de atajo del "malestar patrimonial". La participación, interdisciplinaridad de sus equipos y la inclusión de las comunidades provienen de enfoques museológicos que fueron innovadores a fines del siglo XX como los ecomuseos y museos comunitarios.

Los ecomuseos fueron concebidos en sus orígenes, a inicios de la década de 1970, como distintivos de un territorio en el que el patrimonio formaba parte de la cotidianeidad conservada in situ, de modo que en torno a ese patrimonio la comunidad desarrollaba actividades que dinamizaban su identidad (Acuña 2014). En la base de este concepto propuesto por Varine-Bohan (1985) y difundido en el hemisferio norte, está la noción de territorialidad, también presente en la creación de museos vecinales o de barrio, como el conocido Museo del Barrio en la ciudad de New York de la década de 1960, vigente en tanto foro educativo de promoción, apreciación y comprensión del arte y la cultura de América Latina y su contribución a la estadounidense. Asimismo, La Casa del Museo fundada en la misma época y alineada con la mirada de renovación museológica, subrayó la necesidad de conocer a los públicos a partir de la investigación socioeconómica de las comunidades y así evaluar el impacto de las actividades museográficas y promocionales. Esta propuesta fue antecedente directo de la museología comunitaria que logró su consolidación en la década de 1980 en Oaxaca, y que asumió los acuerdos de la Declaración de la Mesa Redonda de Santiago (1972).
En este gran encuentro mundial se discutió la definición del museo en su relación comunidad y medio ambiente o comunidad y barrio como centro cultural vivo y como punto de encuentro de la comunidad, en oposición al museo elitista, autoritario y de puertas cerradas. De especial importancia fue el llamado a concebir al museo como una institución al servicio de la sociedad, "de la cual es parte inalienable y tiene en su esencia misma los elementos que le permiten participar en la formación de la conciencia de las comunidades a las cuales sirven" (Azócar 2007), de manera de atender a la problemática actual, asumiendo el compromiso con los cambios estructurales imperantes. El propósito de esta reflexión apuntada dentro de la Nueva Museología, fue abandonar la idea de "templo" para los museos, accesibles sólo para las élites y centrados en las colecciones, para dirigir su atención hacia los públicos en la perspectiva de involucrarse con el fortalecimiento de la identidad territorial y el desarrollo de las sociedades en que se emplazan (Tugores y Planas 2006; Yunén 2007). En la restitución actual de esta visión, Hooper-Greenhill (2000, comentado por Buffington 2005) propone el concepto de "post-museo", referido al museo democrático que invita a la comunidad a contribuir y participar en las decisiones sobre la interpretación de las historias o los objetos mostrados. Es también inclusivo en cuanto toma en cuenta las opiniones de grupos minoritarios o marginados (por cultura, clase, etnia, género, religión) y desarrolla prácticas museográficas reflexivas, que genera debate o conversación (Cordón 2018).

Los museos comunitarios alcanzan poco más de 20 años de trayectoria, se han extendido por toda la región incluyendo Chile y conforman en la actualidad la Red de Museos Comunitarios de las Américas, asociados en profundizar la democracia, la sostenibilidad y defensa de la cultura, el territorio, memoria e identidad. Camarena y Morales (2006) destacan en estos museos el desarrollo de procesos de autointerpretación con el que comunidades y pueblos representan su vida como testigos y autores de su propia historia, de manera que se erige en espacio de organización en el que la reflexión sobre la historia desemboca en iniciativas para intervenirla y transformarla. Se privilegia el proceso por sobre el producto acabado, y combina e integra procesos complejos de constitución del sujeto colectivo de la comunidad a través de la reflexión, autoconocimiento y creatividad.

La experiencia paradigmática de los museos comunitarios de Oaxaca puede sintetizarse en cinco grandes lecciones en torno al reconocimiento y valoración de lo local:

1. Las comunidades son actores activos en el cuidado de su patrimonio, lo que amplía las posibilidades de 
conservación y contención frente a las amenazas de saqueo y comercio ilegal dentro y fuera de los países.

2. El desarrollo inmobiliario ocasiona el rescate de grandes volúmenes de material arqueológico que no tiene cabida en los abarrotados espacios de las instituciones establecidas. Los museos comunitarios pueden resguardar esos materiales, conservarlos y exhibirlos in situ en lugar de trasladarlos a museos regionales o nacionales.

3. Esta acción previene el saqueo y la destrucción en los sitios arqueológicos en la medida que la población toma mayor conciencia sobre la importancia del patrimonio cultural.

4. El museo creado para y con la participación ciudadana transforma su función tradicional en el que los públicos acuden a aprender el discurso hegemónico de los especialistas.

5. El patrimonio material e inmaterial es susceptible de valorarse en el museo comunitario bajo una concepción territorial más integral.

Se trata entonces de desmarcarse de la narrativa de los museos tradicionales, buscando maneras de dar mayor reconocimiento y participación a lo local y comunitario.

\section{Discusión y Conclusiones}

En la construcción inclusiva, participativa y crítica de la historia de las culturas y civilizaciones precolombinas los especialistas devienen en agentes catalizadores de procesos de capacitación recíproca con las comunidades en las labores de conservación, museografía, curaduría, gestión y comunicación del patrimonio cultural. Este desafío implica asumir medidas prácticas desde facilitar los espacios al interior del museo en el que los públicos puedan interactuar, experimentar y debatir hasta proveer los elementos que permitan fijar la experiencia vivida en procesos intersubjetivos al interior del mismo museo. Los museos comunitarios de Oaxaca ofrecen un punto de referencia estimulante para el contexto chileno sobre cómo y para qué propiciar iniciativas de fundación de pequeños museos locales y regionales con comunidades ligadas a sociedades indígenas contemporáneas, espacios en los que se puede contextualizar el patrimonio desde otras claves interpretativas distintas a las de los grandes museos nacionales centralizados, debatiendo con la comunidad local y sensibilizándola sobre la conservación in situ (ver ejemplo andino en Narváez 2019 en este número).

Los museos arqueológicos podrían dar a conocer el contexto histórico en una perspectiva territorial más amplia de manera tal que su patrimonio material e inmaterial sea susceptible de valoración e identificación por parte no sólo de sus propios miembros, sino también por otras comunidades. Con esto se propicia el reconocimiento, respeto, participación y vinculación entre comunidades que comparten un mismo territorio. Además, permite difundir de manera transversal y masiva valores culturales propios de un grupo desdeñado.

A través de la historia reciente se han visto casos que las instituciones museísticas son susceptibles de transformarse y adecuarse a las demandas de entornos sociales complejos y cambiantes, y al hecho de que el patrimonio puede y es sujeto de múltiples interpretaciones, por lo que su valoración y significados se transforma a través del tiempo. El enfoque museológico comunitario resulta especialmente oportuno para que los pueblos originarios aymara, quechua, atacameños, coya, diaguita, mapuche, rapanui, yagán y kaweshkar, más las poblaciones afrodescendientes y los migrantes participen del proceso de construcción de un nuevo discurso sobre la diferencia y la diversidad, hacerlo suyo y con ello revitalizar sus identidades culturales.

Estas reflexiones nos llevan a ser conscientes de los procesos de descolonización de los museos que se encuentran en curso en Latinoamérica a propósito de una "visión nerudiana" puesta en crisis ante el escenario actual en el que "la voz propia" al modo de Rigoberta Menchú golpea los fundamentos occidentales y los sesgos de clase y género de los museos y los impele a convertirse en espacios plurivocales. Es decir, que acojan diferentes realidades e identidades, tanto de los pueblos originarios y del resto de la ciudadanía a cuyo pasado dan sentido.

Agradecimientos: A Mariela Santos y Leonor Adán por compartir detalles acerca de la exposición Ayllu y el Museo Leandro Penchulef, respectivamente. $\mathrm{Al}$ equipo editorial interno y externo de Chungara. Al Proyecto CONICYT/PIA ANILLO SOC1405. 


\section{Referencias Citadas}

Acuña, C. 2014. Museos Comunitarios, Territorio e Identidad. Magister en Museología y Gestión del Patrimonio. Facultad de Artes, Universidad Nacional de Colombia.

Alegría, L. y G. Núñez 2007. Patrimonio y modernización en Chile (1910): la Exposición Histórica del Centenario. Atenea 495:69-81.

Alegría, L., S. Gänger y G. Polanco 2009. Momias, cráneos y caníbales. Lo indígena en las políticas de "exhibición" del Estado chileno a fines del siglo XIX. Nuevo Mundo Mundos Nuevos http://nuevomundo.revues.org/53063 (25 mayo 2019).

Ayala, P. 2014. Patrimonialización y arqueología multicultural en San Pedro de Atacama (norte de Chile). Estudios Atacameños, Arqueología y Antropología Surandina 49:69-94.

Azócar, M.A. 2007. A treinta y cinco años de la Mesa Redonda de Santiago. Publicación Ocasional Museo Nacional de Historia Natural 21:14-15.

Buffington, M.L. 2005. Book Review Museums and the Interpretation of Visual Culture, Hooper-Greenhill, E. (2000), National Art Education Association, Virginia. Studies in Art Education 46:275-279.

Burgos, E. 2007. Me llamo Rigoberta Menchú y Así me Nació la Conciencia. Siglo XXI Editores, México, DF.

Camarena, C. y T. Morales 2006. Community Museums and Global Connections. The Union of Community Museums of Oaxaca. editado por I. Karp, C. Kratz, L. Sawaja y T. Ybarra-Frautro, pp. 322-344. Duke University Press, Durham y Londres.

Cordón, D. 2018. Evolución conceptual del museo como espacio comunicativo. Estudios sobre el Mensaje Periodístico 24:485-500.

Crow J. 2009. Narrating the Nation: Chile's Museo Historico Nacional. National Identities 11:109-126.

Crow, J. 2011. The Mapuche Museum of Cañete (1968-2010): Decolonising the Gaze. Journal of Latin American Cultural Studies 20:161-178

DeCarli, G. 2008. Eduquémonos para educar: panorama latinoamericano sobre iniciativas de formación. Museos, Educación y Juventud, Memorias del V Encuentro Regional de América Latina y el Caribe sobre Educación y Acción Cultural en Museos CECA ICOM, pp. 43-52. Ministerio de Cultura, Bogotá.

Earle, R. 2006. Monumentos y museos: la nacionalización del pasado precolombino en la Hispanoamérica decimonónica. En Galerías del Progreso: Museos, Exposiciones y Cultura Visual en América Latina, editado por B. González Stephan y J. Andermann, pp. 27-56. Beatriz Viterbo Editora, Buenos Aires.

Gazmuri, C. 2001. El Chile del Centenario, los Ensayistas de la Crisis. Editorial Pontificia Universidad Católica de Chile, Santiago.

Gil, M. 2016. Exhibiting the Nation: Indigenousness in Chile's National Museums. Museum and Society 14:82-97.

Gnecco, C. 2008. Discursos sobre el otro: pasos hacia una arqueología de la alteridad étnica. Revista Ciencias Sociales 2:101-129.

Hernández, C. 2006. Chile a fines del siglo XIX: Exposiciones, museos y la construcción del arte nacional. En Galerías del Progreso: Museos, Exposiciones y Cultura Visual en América Latina, editado por B. González Stephan y J. Andermann, pp. 261293. Beatriz Viterbo Editora, Buenos Aires.

ICOMOS 1999. Carta internacional de turismo cultural 1977 La gestión del turismo en los sitios con patrimonio significativo. Cuadernos de Sociomuseología 15:181-185.

Mamani, M.C. 1989. History and prehistory in Bolivia: what about the Indians? En Conflict in the Archaeology of Living
Traditions, editado por R. Layton, pp. 46-59. Unwin Hyman, Londres.

MCAP Ministerio de las Culturas, las Artes y el Patrimonio de Chile 2016. Alberto Serrano: hombre austral (junio 2016). Revista Patrimonio de Chile. http://www.patrimoniodechile.cl/688/w3article-74355.html?_noredirect=1 (25 mayo de 2019).

Molloy, S. 2005. De exhibiciones y despojos. Reflexiones sobre el patrimonio nacional a principios del siglo XX. En El Salto de Minerva: Intelectuales, Género y Estado en América Latina, editado por M. Moraña y M. Olivera-Williams, pp. 143-155. Iberoamericana Editorial Vervuert, Frankfurt.

Muñoz, I. y V.G. Standen 2018. Museo Arqueológico San Miguel de Azapa: 50 años de investigación, protección y difusión del patrimonio cultural de la región de Arica y Parinacota. Chungara Revista de Antropología Chilena 50 (1):3-4.

Museo Leandro Penchulef 2014. http://museoleandropenchulef. uc.cl (25 mayo de 2019).

MASMA Museo Universidad de Tarapacá San Miguel de Azapa 2019. http://masma.uta.cl/ (25 mayo de 2019).

Narváez, L.A. 2019. El Museo Túcume y la nueva museología. Chungara Revista de Antropología Chilena 51 (2):291-304.

Navarro, O. 2006. Museos nacionales y representación: Ética, museología e historia. ICOFOM Study Series 35:365-373.

Neruda, P. 2005. Canto General. Pehuén, Santiago.

Podgorny I. y G. Politis 1992. ¿Qué sucedió en la historia? Los esqueletos araucanos del Museo de La Plata y la conquista del desierto. Arqueología Contemporánea 3:73-79.

Podgorny, I. y M.M. Lopes 2013. Trayectorias y desafíos de la historiografía de los museos de historia natural en América del Sur. Anais do Museu Paulista 21:15-25.

Red de Museos de la Región de Los Ríos 2019. http:// museosregiondelosrios.cl/index.php/museos-por-geografia/ cordillera-y-lagos/5-museo-despierta-hermano-malalhue.

Salazar, D., V. Figueroa, D. Morata y G. Manríquez 2011. Metalurgia en San Pedro de Atacama durante el período Medio: nuevos datos, nuevas preguntas. Revista Chilena de Antropología 23:123-148.

Schell, P. 2001. Capturing Chile: Santiago's Museo Nacional during the nineteenth century. Journal of Latin American Cultural Studies $10: 45-65$.

SNPC Servicio Nacional del Patrimonio Cultural de Chile 2019. Registro de museos. http://www.registromuseoschile.cl/663/w3propertyvalue-76806.html.

Subercaseaux, B. 2000. Historia del Libro en Chile. Editorial LOM, Santiago.

Tugores, F. y R. Planas 2006. Introducción al Patrimonio Cultural. EdicionesTrea, Gijón.

Varine-Bohan, H. 1985. El ecomuseo, más allá de la palabra. Revista de los Museos de Andalucía 8:19-29.

Yaeger, G. 2009. Sobrellevar el pasado español. Liberalismo hispanoamericano y la carga de la historia colonial en el siglo XIX: el caso chileno. En Nación y Nacionalismo en Chile. Siglo XIX, editado por A. San Francisco y G. Cid, pp. 117-136. Centro de Estudios Bicentenario, Santiago.

Yunén, R.E. 2007. ¿Museología Nueva? ¡Museografía Nueva! www. 673 nuevamuseología.com.ar/RafaelYunen.htm. 